Article

\title{
Comparative Analysis of Radical Adduct Formation (RAF) Products and Antioxidant Pathways between Myricetin-3-O-Galactoside and Myricetin Aglycone
}

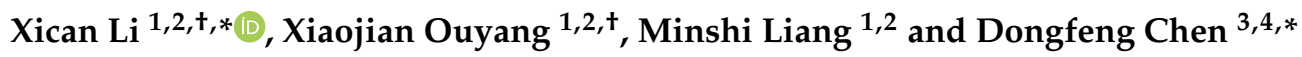 \\ 1 Innovative Research \& Development Laboratory of TCM of Guangdong Province, University of Chinese \\ Medicine, Guangzhou 510006, China \\ 2 School of Chinese Herbal Medicine; Guangzhou University of Chinese Medicine, Guangzhou 510006, China \\ 3 School of Basic Medical Science, Guangzhou University of Chinese Medicine, Guangzhou 510006, China \\ 4 The Research Center of Integrative Medicine, Guangzhou University of Chinese Medicine, \\ Guangzhou 510006, China \\ * Correspondence: lixican@126.com (X.L.); chen888@gzucm.edu.cn (D.C.) \\ + These authors contributed equally to this work.
}

Received: 10 July 2019; Accepted: 29 July 2019; Published: 30 July 2019

check for updates

\begin{abstract}
The biological process, 3-O-galactosylation, is important in plant cells. To understand the mechanism of the reduction of flavonol antioxidative activity by 3-O-galactosylation, myricetin-3-O-galactoside (M3OGa) and myricetin aglycone were each incubated with $2 \mathrm{~mol}$ $\alpha, \alpha$-diphenyl- $\beta$-picrylhydrazyl radical $\left(\mathrm{DPPH}^{\bullet}\right)$ and subsequently comparatively analyzed for radical adduct formation (RAF) products using ultra-performance liquid chromatography coupled with electrospray ionization quadrupole time-of-flight tandem mass spectrometry (UPLC-ESI-Q-TOF-MS) technology. The analyses revealed that M3OGa afforded an M3OGa-DPPH adduct $(\mathrm{m} / z$ 873.1573) and an M3OGa-M3OGa dimer ( $\mathrm{m} / \mathrm{z}$ 958.1620). Similarly, myricetin yielded a myricetin-DPPH adduct $(\mathrm{m} / \mathrm{z}$ 711.1039) and a myricetin-myricetin dimer $(\mathrm{m} / \mathrm{z}$ 634.0544). Subsequently, M3OGa and myricetin were compared using three redox-dependent antioxidant analyses, including $\mathrm{DPPH}^{\bullet}$-trapping analysis, 2-phenyl-4,4,5,5-tetramethylimidazoline-1-oxyl 3-oxide radical (PTIO')-trapping analysis, and ${ }^{\bullet} \mathrm{O}_{2}$ inhibition analysis. In the three analyses, M3OGa always possessed higher $\mathrm{IC}_{50}$ values than those of myricetin. Conclusively, M3OGa and its myricetin aglycone could trap the free radical via a chain reaction comprising of a propagation step and a termination step. At the propagation step, both M3OGa and myricetin could trap radicals through redox-dependent antioxidant pathways. The 3-O-galactosylation process, however, could limit these pathways; thus, M3OGa is an inferior antioxidant compared to its myricetin aglycone. Nevertheless, 3-O-galactosylation has a negligible effect on the termination step. This 3-O-galactosylation effect has provided novel evidence that the difference in the antioxidative activities of phytophenols exists at the propagation step rather than the termination step.
\end{abstract}

Keywords: myricetin-3-O-galactoside; myricetin; 3-O-galactosylation; antioxidant pathway; radical adduct formation

\section{Introduction}

Galactosylation is an important biological process in cellular metabolism [1,2] that is catalyzed by certain enzymes, such as bovine $\beta$ (1,4)-galactosyltransferase [2], Sb3GT1 (UGT78B4) [3], AgUCGalT1 [4], and $\alpha$-1,3-galactosyltransferase ( $\alpha 3 \mathrm{GalT}$ ) [5]. Through galactosylation, plant cells can link a galactose residue to the 3-O atom in flavonol. This process is termed "3-O-galactosylation" [6]. The 3-Ogalactosylation process results in extensive coexistence of flavonol 3-O-galactoside and flavonol 
aglycone in the same plant. Thus far, at least six pairs of flavonol 3-O-galactoside and flavonol aglycone have been found in identical plants (Supplementary File S1) [7-12].

Flavonol is well known as an effective natural antioxidant. Experimental [13-15] and theoretical studies [16-18] have indicated that the antioxidant activity of flavonol is closely associated with the presence of 3-OH. Accordingly, 3-O-galactosylation is believed to reduce the antioxidant activity of flavonol, although no study on the mechanism of this reduction has been conducted.

Consequently, myricetin-3-O-galactoside (M3OGa) and its myricetin aglycone were selected as the representatives for the comparative study. As shown in Figure 1A, M3OGa bears a $\beta$-galactose residue at its 3-O position; thus, it can be regarded as the 3-O-galactosylation derivative of myricetin. If any difference in their antioxidant activities exists, it can be attributed to 3-O-galactosylation. Recently, M3OGa has been reported to coexist with its myricetin aglycone in white myrtle [11] and Nelumbo nucifera [12]. Their coexistence in the same plant has actually enhanced the comparability and biologically relevance of this comparative study.

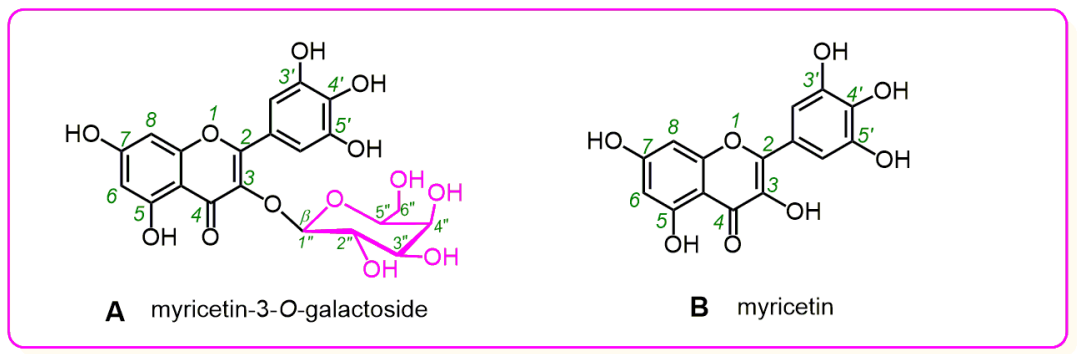

Figure 1. Structures of myricetin-3-O-galactoside (M3OGa) (A) and myricetin (B).

In the comparative study, the final products of the interaction of M3OGa and myricetin aglycone with $\alpha, \alpha$-diphenyl- $\beta$-picrylhydrazyl radical $\left(\mathrm{DPPH}^{\bullet}\right)$ were severally analyzed using leading-edge ultra-performance liquid chromatography coupled with electrospray ionization quadrupole time-of-flight tandem mass spectrometry (UPLC-ESI-Q-TOF-MS) technology to test the possibility of radical adduct formation (RAF). The high resolution of the Q-TOF-MS technology ensures the reliability of the chemical analysis. Based on the RAF product analysis, M3OGa and myricetin were further investigated for their antioxidant pathways using relevant chemical approaches. Expectedly, the series of investigative experiments will provide profound knowledge on the mechanism of the reduction of the antioxidant activity of flavonol by 3-O-galactosylation.

In addition, the understanding of the 3-O-galactosylation process is expected to be of benefit to other types of 3-O-glycosylation processes, such as 3-O-glucosylation, 3-O-rhamnglycosylation, and 3-O-arabinosylation. This is because these 3-O-glycosylation processes are essentially not different from 3-O-galactosylation, and flavonoid-3-O-glycosides are present in plants (e.g., myricetin-3-O-glucoside, myricetin-3-O-rhamnoside, and myricetin-3-O-arabinoside). From an antioxidant chemistry viewpoint, flavonol (or its glucoside) has the same antioxidant pathways as those of other phytophenols [19-22]. Thus, the analysis of the RAF products, based on the UPLC-ESI-Q-TOF-MS technology, will provide novel and reliable insights on the antioxidant chemistry of all types of phytophenols, especially flavonoid 3-O-glucosides (e.g., isorhamnetin 3-O-galactoside [7], hyperin [8], trifolin [9], and syringetin 3-O-galactoside [10]) and anthocyanin 3-O-galactosides (e.g., cyanidin-3-O-galactoside [23] and delphinidin-3-O-galactoside [24]).

\section{Results and Discussion}

According to previous reports $[25,26]$, phytophenol antioxidants can afford final products through the RAF reaction when they interact with free radicals [27-29]. Thus, the RAF product analysis may be a potential tool for exploring antioxidant chemistry. The present study, however, used cut-edging UPLC-ESI-Q-TOF-MS technology to analyze the RAF products of M3OGa and myricetin interacting with $2 \mathrm{~mol} \mathrm{DPPH} \bullet$ radical. 
After treatment with 2 mol DPPH ${ }^{\bullet}, 1$ mol of M3OGa yielded a chromatographic peak at a retention time (Rt) of $2.486 \mathrm{~min}$ in the analysis. Moreover, the peak further afforded an $\mathrm{m} / \mathrm{z} 873.1573$ molecular ion peak in the MS spectra (Figure 2D). This value $(\mathrm{m} / \mathrm{z} 873.1573)$ represented the loss of exactly one $\mathrm{H}$ atom ( $\mathrm{m} / z 1.0091$ [30]) as compared to the sum of the molecular weights of M3OGa $(\mathrm{m} / z 480.0858)$ and $\mathrm{DPPH}^{\bullet}(\mathrm{m} / \mathrm{z}$ 394.0806, Supplementary File S2). Thereby, M3OGa may combine with DPPH to generate an $\mathrm{H}$ atom and an adduct. The adduct can be further verified by the two characteristic fragments, $m / z 196$ and 226 (Figure 2F). Our previous studies indicated that DPPH ${ }^{\bullet}$ or the DPPH adduct always affords $m / z 196$ and 226 fragments in the negative ion model MS spectra [13,27,31-34]. Considering that the above adduct is indeed M3OGa-DPPH, the relative deviation between the experimental value $\left(\mathrm{m} / \mathrm{z}\right.$ 872.1482) and the calculated molecular weight value (M.W. 872.1535) was only $6.1 \times 10^{-6}$. Therefore, an M3OGa-DPPH adduct was definitively formed when M3OGa interacted with DPPH ${ }^{\bullet}$. Based on previously reported studies [13,27,31-34], the MS spectra of the M3OGa-DPPH adduct could be elucidated, as shown in Figure 3A.

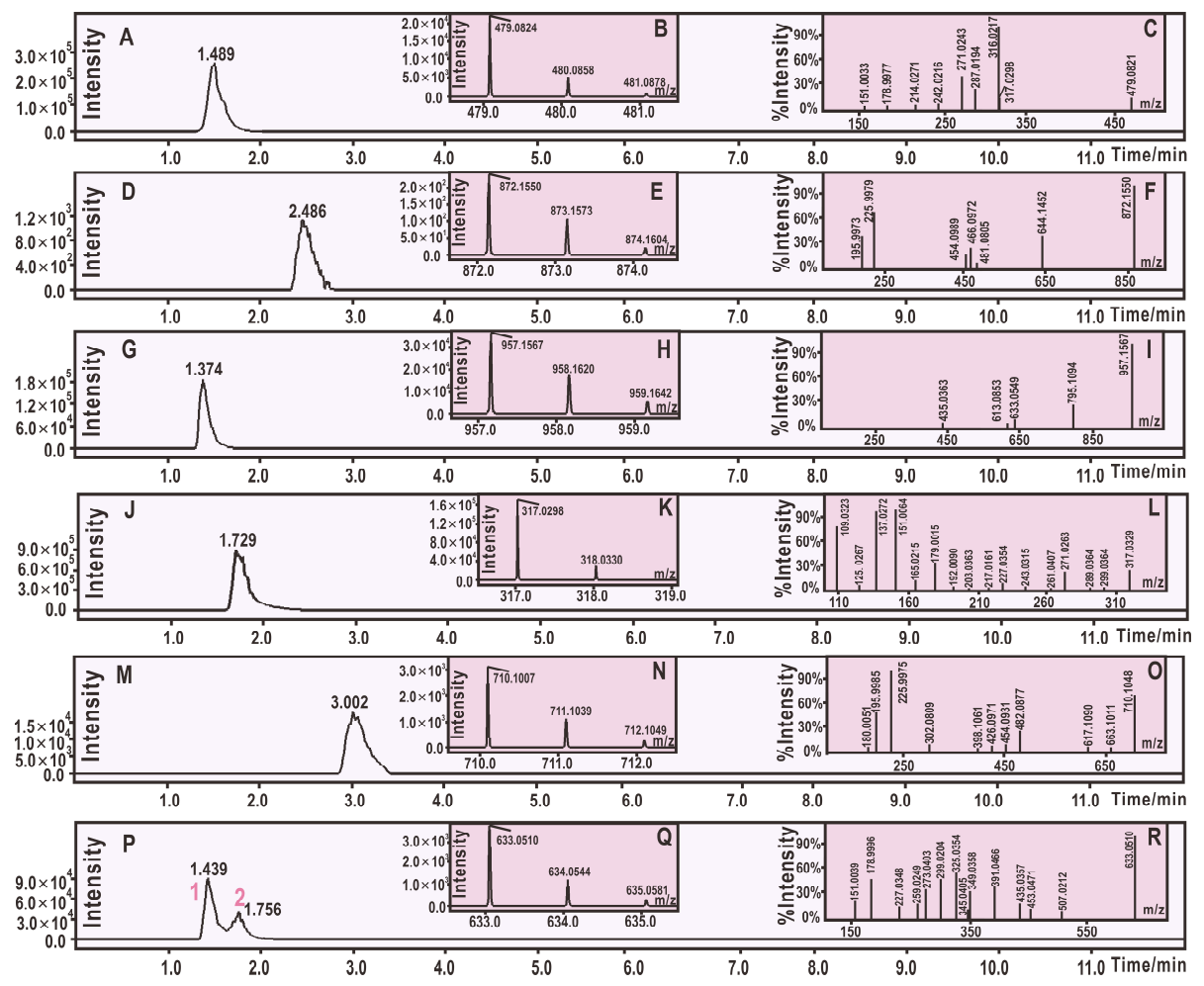

Figure 2. Typical results of the UPLC-ESI-Q-TOF-MS analysis: (A) Chromatogram of myricetin-3O-galactoside (M3OGa) when the formula, $\left[\mathrm{C}_{21} \mathrm{H}_{20} \mathrm{O}_{13}-\mathrm{H}\right]^{-}$, was extracted; (B) primary MS spectra of $\mathrm{M} 3 \mathrm{OGa}$; (C) secondary MS spectra of $\mathrm{M} 3 \mathrm{OGa}$; (D) chromatogram of the radical adduct formation (RAF) product of M3OGa-DPPH when the formula, $\left[\mathrm{C}_{39} \mathrm{H}_{31} \mathrm{~N}_{5} \mathrm{O}_{19}-\mathrm{H}\right]^{-}$, was extracted; (E) primary MS spectra of the RAF product of M3OGa-DPPH; (F) secondary MS spectra of the RAF product of M3OGa-DPPH; (G) chromatogram of possible dimeric products of M3OGa when the formula, $\left[\mathrm{C}_{42} \mathrm{H}_{38} \mathrm{O}_{26}-\mathrm{H}\right]^{-}$, was extracted; $(\mathbf{H})$ primary MS spectra of possible dimeric products of M3OGa; (I) secondary MS spectra of the RAF product of the dimeric products of M3OGa; (J) chromatogram of myricetin when the formula, $\left[\mathrm{C}_{15} \mathrm{H}_{10} \mathrm{O}_{8}-\mathrm{H}\right]^{-}$, was extracted; $(\mathbf{K})$ primary MS spectra of myricetin; (L) secondary MS spectra of myricetin; (M) chromatogram of the RAF product of myricetin-DPPH when the formula, $\left[\mathrm{C}_{33} \mathrm{H}_{21} \mathrm{~N}_{5} \mathrm{O}_{14}-\mathrm{H}\right]^{-}$, was extracted; $(\mathbf{N})$ primary MS spectra of the RAF product of myricetin-DPPH; $(\mathbf{O})$ secondary MS spectra of the RAF product of myricetin-DPPH; $(\mathbf{P})$ chromatogram of possible dimeric products of M3OGa when the formula, $\left[\mathrm{C}_{30} \mathrm{H}_{18} \mathrm{O}_{16}-\mathrm{H}\right]^{-}$, was extracted; $(\mathbf{Q})$ primary MS spectra of possible dimeric products of myricetin; (R) secondary MS spectra of the RAF product of the dimeric products of myricetin. 


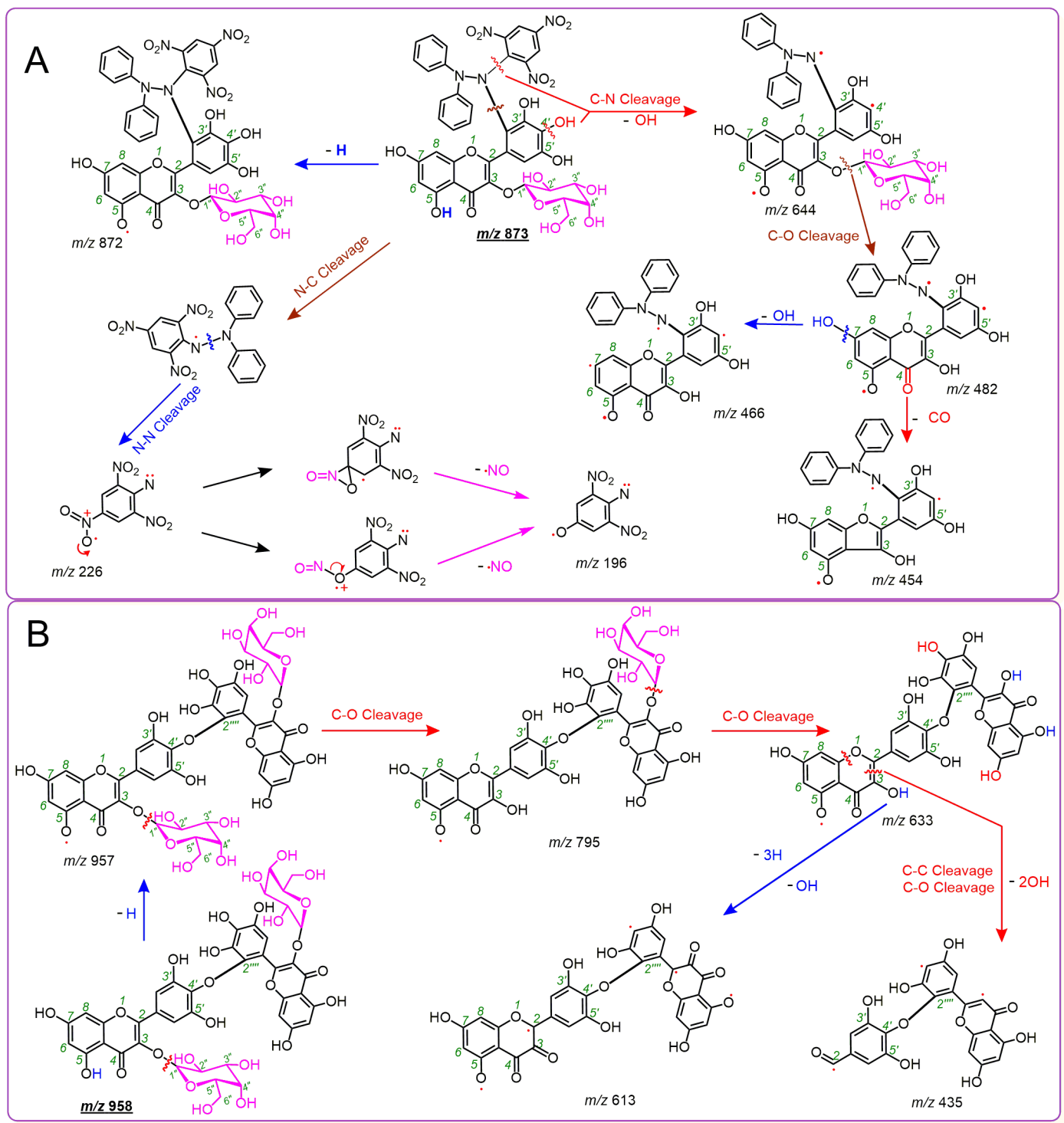

Figure 3. Proposed MS elucidations of the RAF reaction products between M3OGa and the DPPH radical. (A) M3OGa-DPPH adduct; (B) M3OGa-M3OGa dimer (the MS spectra were in the negative ion mode. The accurate $m / z$ values are simply expressed as integers. Other linking sites between the M3OGa and DPPH moieties and other reasonable cleavages should not be excluded in the MS elucidation).

Besides the adduct, a flavonol dimer was formed from the interaction with the free radical [35]. As illustrated in Figure 2G-H, M3OGa $(\mathrm{m} / \mathrm{z} 480.0858)$ afforded an MS peak with $\mathrm{m} / \mathrm{z} 958.1620$ at an Rt of 1.374 min. This strongly indicates that two M3OGa molecules dimerized into M3OGa-M3OGa. During the dimerization process, two $\mathrm{H}$ atoms may have been lost via $\mathrm{H}$ atom transfer (HAT) pathways (see below).

Thus, it is clear that M3OGa treated with $2 \mathrm{~mol} \mathrm{DPPH}^{\bullet}$ can yield an M3OGa-DPPH adduct and an M3OGa-M3OGa dimer. The adduct and dimer are the two main products of the RAF reactions. Similarly, myricetin could also produce a myricetin-DPPH adduct and myricetin-myricetin dimers (Figure $2 \mathrm{M}-\mathrm{P}$ ). The proposed RAF products of the myricetin reaction with $\mathrm{DPPH}^{\bullet}$ and their MS elucidations are shown in Figure 4. The generation of two types of RAF products, however, could offer further insights into the antioxidant chemistry of M3OGa and myricetin. Considering that the reaction proceeds via a concerted pathway, excessive $\mathrm{DPPH}^{\bullet}(2 \mathrm{~mol})$ will synchronously link the M3OGa molecule to produce an M3OGa-DPPH adduct and no M3OGa-M3OGa dimer. Conversely, considering 
that the reaction is ion-mediated (rather than radical-mediated), M3OGa may be converted into M3OGa $\left(\right.$ or $\mathrm{M} 3 \mathrm{OGa}^{\Theta}$ ). $\mathrm{M} 3 \mathrm{OGa}$ (or $\mathrm{M} 3 \mathrm{OGa}^{\Theta}$ ) ions cannot link with each other. The co-existence of the M3OGa-DPPH adduct and M3OGa-M3OGa dimer in the product mixture strongly suggests that the DPPH-trapping reaction of M3OGa is a radical-mediated stepwise reaction. The reactivity of the free radicals is so high that their stepwise reaction becomes a chain reaction. This agrees with the previous literatures $[36,37]$. Furthermore, the literature has indicated that radical-trapping chain reactions can

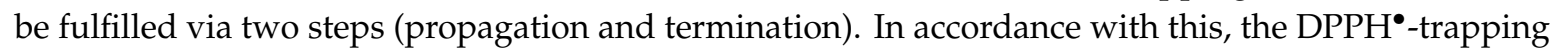
reaction of M3OGa can be proposed, as shown in Figure 5.

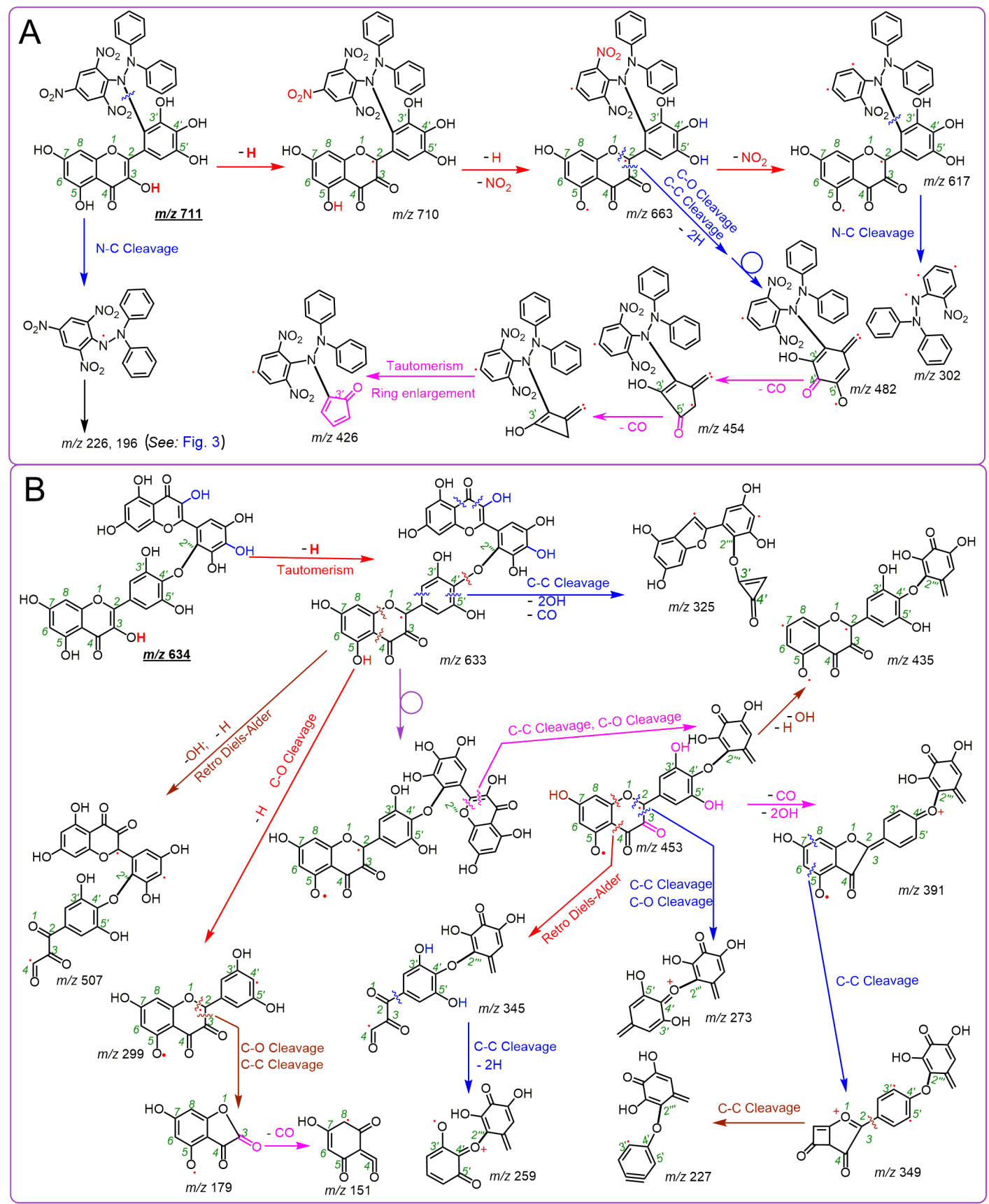

Figure 4. Proposed MS elucidations of the RAF reaction products between myricetin and the DPPH radical. (A) Myricetin-DPPH adduct; (B) myricetin-myricetin dimer (the MS spectra were in the negative ion mode. The circle indicates $\sigma$ bond rotation. The accurate $m / z$ values are simply expressed as integers. Other linking sites between the myricetin and DPPH moieties and other reasonable cleavages should not be excluded in the MS elucidation). 


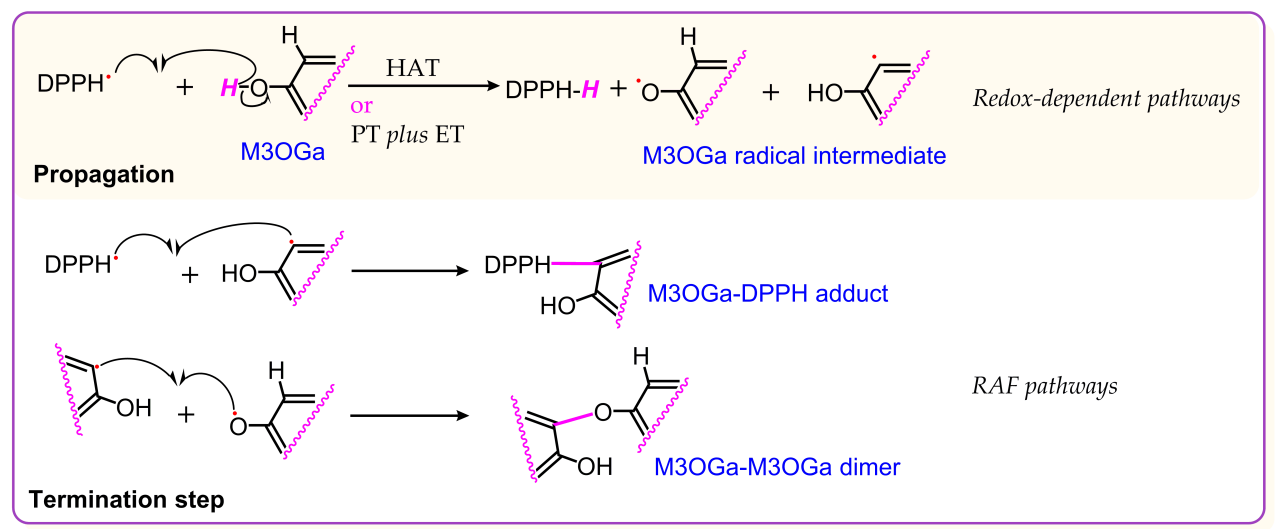

Figure 5. Proposed chain reaction of M3OGa trapping 2 mol DPPH

As shown in Figure 5, the intermediate radicals play a key role in the radical chain reaction. Intermediate radicals were formed when $\mathrm{DPPH}^{\bullet}$ accepted an $\mathrm{H}$ atom $\left(\mathrm{H}^{\bullet}\right)$ and the M3OGa antioxidant donated an $\mathrm{H}$ atom $\left(\mathrm{H}^{\bullet}\right)$. Several successful pathways have been reported to achieve this change. The first pathway is called the HAT pathway, where an $\mathrm{H}$ atom as one unit is directly transferred from an antioxidant molecule to a free radical. In fact, HAT has been suggested as the main pathway of the $\mathrm{DPPH}^{\bullet}$-trapping reaction [38]. The results in Supplementary File S3 show that M3OGa and myricetin increased their $\mathrm{DPPH}^{\bullet}$-trapping abilities in a dose-dependent manner, implying that both M3OGa and myricetin might have performed their antioxidant activities via the HAT pathway. This may responsible for the above observation of $m / z 1.0091$.

Besides the HAT pathway, other pathways may also occur, including mere electron transfer (ET) and ET plus proton transfer (PT). Furthermore, the ET plus proton transfer pathway can be classified into four subtypes, i.e., proton loss single electron transfer (SPLET) [19,37,39-41], sequential electron-proton transfer (SEPT) [42], proton-coupled electron transfer (PCET) [19,37,40,41,43], and concerted proton-electron transfer (CPET) [44]. To test the possibility of the ET pathway, M3OGa and myricetin were determined using $\mathrm{PTIO}^{\bullet}$-trapping at $\mathrm{pH}$ 4.5. Cyclic voltammetry evidence indicated that $\mathrm{PTIO}{ }^{\bullet}$-trapping at $\mathrm{pH} 4.5$ is an ET-mediated process [45]. The results in Supplementary File S3 show that $\mathrm{M} 3 \mathrm{OGa}$ and myricetin effectively trapped the $\mathrm{PTIO}^{\bullet}$ radical at $\mathrm{pH} 4.5$, implying that they were able to undergo ET to trap the radical during the propagation step. At $\mathrm{pH}$ 7.4, M3OGa and myricetin could also dose-dependently trap the $\mathrm{PTIO}^{\bullet}$ radical (Supplementary File S3). However, their $\mathrm{IC}_{50}$ values were lower than those at $\mathrm{pH} 4.5$ (Table 1). These effects of $\mathrm{pH}$ suggest that the $\mathrm{H}^{+}$-transfer pathway might mediate $\mathrm{PTIO}^{\bullet}$-trapping during the propagation step. In short, the $\mathrm{PTIO}^{\bullet}$-trapping analyses at both $\mathrm{pH} 4.5$ and 7.4 indicate that ET plus PT serve as the antioxidative pathway of M3OGa and myricetin in physiological aqueous solution.

Table 1. $\mathrm{IC}_{50}$ values $(\mu \mathrm{M})$ of $\mathrm{M} 3 \mathrm{OGa}$ and myricetin in the antioxidant spectrophotometric analyses.

\begin{tabular}{cccc}
\hline Antioxidant Analyses & M3OGa & Myricetin & Trolox \\
\hline DPPH $^{\bullet}$-trapping & $12.9 \pm 0.3^{\mathrm{b}}$ & $10.7 \pm 0.3^{\mathrm{a}}$ & $26.4 \pm 2.5$ \\
$\mathrm{PTIO}^{\bullet}$-trapping (pH 4.5) & $263.7 \pm 3.5^{\mathrm{b}}$ & $132.9 \pm 5.1^{\mathrm{a}}$ & $220.1 \pm 4.6$ \\
$\mathrm{PTIO}^{\bullet}$-trapping (pH 7.4) & $131.2 \pm 5.1^{\mathrm{b}}$ & $81.5 \pm 2.4^{\mathrm{a}}$ & $142.9 \pm 5.0$ \\
$\bullet^{\circ} \mathrm{O}^{-}$-trapping & $88.9 \pm 7.2^{\mathrm{b}}$ & $73.3 \pm 1.9^{\mathrm{a}}$ & $2777.5 \pm 35.3$ \\
\hline
\end{tabular}

The $\mathrm{IC}_{50}$ value (in $\mu \mathrm{M}$ ) was defined as the final concentration of $50 \%$ radical inhibition or relative reducing power, determined by linear regression analysis and expressed as the mean $\pm \operatorname{SD}(n=3)$. The linear regression was analyzed using version 6.0 of the Origin professional software. The $\mathrm{IC}_{50}$ values with different superscripts $(\mathrm{a}$ or $\mathrm{b})$, between M3OGa and myricetin, are significantly different $(p<0.05)$. Trolox is the positive control. The dose response curves are listed in Supplementary File S3, Figures S1-S4.

The above two free radicals, $\mathrm{PTIO}^{\bullet}$ and $\mathrm{DPPH}^{\bullet}$, actually cannot be found in cells, and they are merely chemical probes for antioxidant study. Dissimilar to the case with the two free radicals, 
the superoxide radical $\left({ }^{\bullet} \mathrm{O}_{2}^{-}\right)$occurs in cells and is a member of the reactive oxygen species (ROS) family. Previous studies have suggested that the scavenging of the superoxide radical is involved in ET and PT [46-50]; this was further supported by our observations that M3OGa and myricetin successfully scavenged ${ }^{\bullet} \mathrm{O}_{2}{ }^{-}$in a concentration-dependent manner (Supplementary File S3).

Moreover, all these antioxidant pathways involve ET, which is the basis of the redox reaction. Therefore, these pathways could be collectively termed as redox-dependent pathways. The redox-dependent pathways, however, occur predominantly in the propagation step (Figure 5). In these redox-dependent antioxidant analyses, M3OGa always afforded higher $\mathrm{IC}_{50}$ values $(\mu \mathrm{M})$ than those of myricetin (Table 1), suggesting that the 3-O-galactosylation process limits the redox-dependent pathways in the propagation step. Such a detrimental effect may be attributed to the fact that 3-O-galactosylation has reduced the amount of phenolic-OH. In addition, the conformation analysis revealed that the 3-O-galactosylation process introduces a bulky $\beta$-galactose residue to twist the planar molecule (Figure 6). The breakage of the planarity has been reported to weaken the $\pi-\pi$ conjugation [51] and further reduce the antioxidant activity [52]. This makes M3OGa an inferior antioxidant compared to its myricetin aglycone.

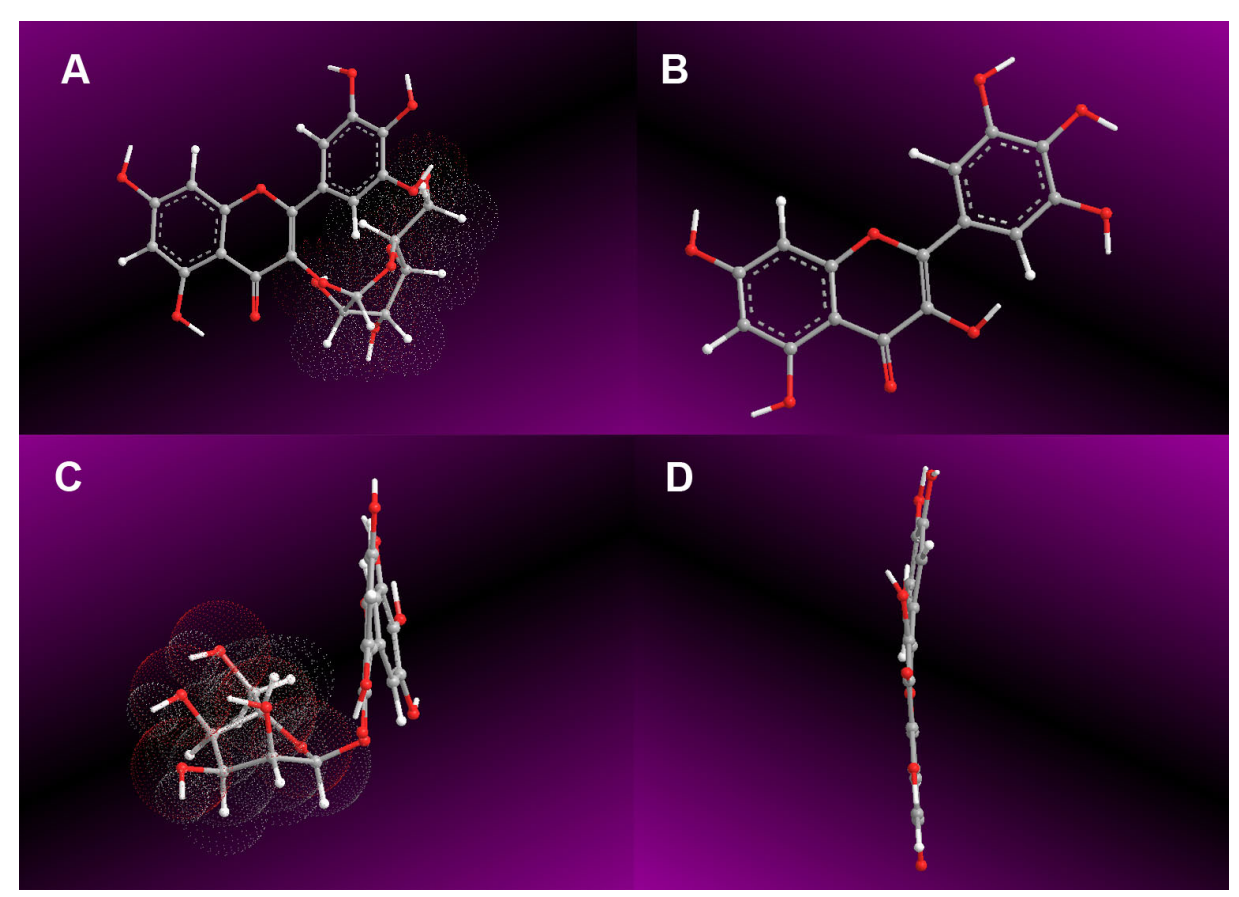

Figure 6. Preferential conformations of myricetin-3-O-galactoside (M3OGa) and myricetin. (A) Front view of $\mathrm{M} 3 \mathrm{OGa}$; (B) front view of myricetin; (C) right side view of $\mathrm{M} 3 \mathrm{OGa}$; (D) right side view of myricetin. The preferential conformation was analyzed using the Chem3D Pro14.0 program (PerkinElmer, Waltham, MA, USA).

Nevertheless, M3OGa and myricetin have previously been shown to similarly produce a dimer product and an adduct product when interacting with the DPPH radical. This similarity indicates that the 3-O-galactosylation process could slightly affect the RAF pathways and that it plays a negligible role in the termination step. In other words, 3-O-galactosylation, as one of the structural factors in phytophenols, can only undergo the propagation step to exert its effect.

Besides the 3-O-galactosylation process, other structural factors may also affect the antioxidant activity of phytophenols, such as C-glycosidation, glucuronidation, isoprenylation, methylation, geometrical configuration, and p-coumaroylation [32,52-56]. However, the effects of all these structural factors were thought to be concentrated in the propagation step.

As reported in the literature [19,37], during the chain reaction, the propagation step proceeds via the HAT (or ET plus PT) pathway to generate intermediate radicals. The previous literature has 
suggested that if undergoing the HAT pathway, phytophenols may require $77.0-86.7 \mathrm{kcal} / \mathrm{mol} \mathrm{BDE}$ (bond dissociation enthalpy or bond dissociation energy) to produce intermediate radicals [19,37]. However, if undergoing the ET plus PT pathway, phytophenols may require ionization energy (IE) and vertical electron affinity (EA) $[57,58]$. For instance, the IE and EA values of the xanthones family were $100 \mathrm{kcal} / \mathrm{mol}$ and $40 \mathrm{kcal} / \mathrm{mol}$, respectively [59]. This implies that the generation of radicals is always difficult, regardless of the antioxidant pathway employed.

The termination step, however, occurs predominantly via the RAF pathway, a bonding reaction. Conventionally, the bonding reaction is exothermic; thus, the termination step is spontaneous and rapid. Therefore, the rate at which the antioxidant traps the free radical depends on the propagation step, and the propagation step is the rate-determining step of the whole radical trapping process of phytophenols. The structural factors (such as skeleton or substitute) can classify phytophenols into different types or subtypes; however, they can only impose their effects during the propagation step and not the termination step. Conversely, phytophenols have essentially no difference in their antioxidant chemistry, and their antioxidant reactions are radical-mediated chain reactions [19-22]. Thus, it can be inferred that for the phytophenols family, the differentiation of antioxidant activities may occur at the propagation step rather than the termination step. Generally, this was in agreement with our novel evidence.

\section{Materials and Methods}

\subsection{Chemicals}

M3OGa $\left(\mathrm{C}_{21} \mathrm{H}_{20} \mathrm{O}_{13}\right.$, CAS number: 15648-86-9, M.W.: 480.4, purity: 98\%, Supplementary File $\left.\mathrm{S} 4\right)$ was obtained from BioBioPha Co., Ltd. (Kunming, China); myricetin $\left(\mathrm{C}_{15} \mathrm{H}_{10} \mathrm{O}_{8}, \mathrm{CAS}\right.$ number: 529-44-2, M.W.: 318.2, purity: 98\%, Supplementary File S5) was obtained from Chengdu Biopurify Phytochemicals Ltd. (Chengdu, China). Pyrogallol and ( \pm )-6-hydroxyl-2,5,7,8-tetramethylchromane-2-carboxylic acid (Trolox) were obtained from Sigma-Aldrich (Shanghai, China). The $\alpha, \alpha$-Diphenyl- $\beta$-picrylhydrazyl radical ( $\mathrm{DPPH}^{\bullet}, \mathrm{C}_{18} \mathrm{H}_{12} \mathrm{~N}_{5} \mathrm{O}_{6}$ ) was obtained from Aladdin Chemical Ltd. (Shanghai, China). The 2-phenyl-4,4,5,5-tetramethylimidazoline-1-oxyl-3-oxide radical (PTIO•) was obtained from TCI Chemical Co. (Shanghai, China). Tris-hydroxymethyl amino methane (Tris) was obtained from Dingguo Biotechnology Ltd. (Beijing, China). Methanol and the other reagents were purchased from Guangdong Guanghua Chemical Plants Co., Ltd. (Shantou, China).

\subsection{UPLC-ESI-Q-TOF-MS Analysis of DPPH• Reaction Products with M3OGa and Myricetin}

The reaction of $\mathrm{DPPH}^{\bullet}$ with M3OGa and its myricetin aglycone proceeded under the conditions described in a previous paper [60]. In brief, a methanol solution of M3OGa was mixed with a methanol $\mathrm{DPPH}^{\bullet}$ solution with a molar ratio of 1:2, and the resulting mixture was incubated for $24 \mathrm{~h}$ at room temperature. Subsequently, the product was passed through a $0.22 \mu \mathrm{m}$ filter for UPLC-ESI-Q-TOF-MS analysis.

The UPLC-ESI-Q-TOF-MS analysis was based on the method described in our previous study [61]. The UPLC-ESI-Q-TOF-MS analysis system was equipped with a Phenomenex Luna $\mathrm{C}_{18}$ column $(2.1 \mathrm{~mm}$ inner diameter $\times 100 \mathrm{~mm}, 1.6 \mu \mathrm{m}$, Phenomenex Inc., Torrance, CA, USA). The mobile phase was employed for the elution of the system and consisted of a mixture of methanol (phase A) and $0.1 \%$ formic acid water (phase B). The column was eluted at a flow rate of $0.2 \mathrm{~mL} / \mathrm{min}$ with the following gradient elution program: 0-2 min, maintain 30\% B; $2-10 \mathrm{~min}, 30-0 \% \mathrm{~B} ; 10-12 \mathrm{~min}, 0-30 \% \mathrm{~B}$. The sample injection volume was set at $3 \mu \mathrm{L}$ for the separation of the different components. The Q-TOF-MS analysis was performed on a Triple TOF $5600^{\text {plus }}$ mass spectrometer (AB SCIEX, Framingham, MA, USA) equipped with an ESI source, which was run in the negative ionization mode. The scan range was set at 100-2000 Da. The system was run with the following parameters: ion spray voltage, $-4500 \mathrm{~V}$; ion source heater temperature, $550{ }^{\circ} \mathrm{C}$; curtain gas pressure (CUR, $\mathrm{N}_{2}$ ), 30 psi; nebulizing gas pressure (GS1, Air), 50 psi; Tis gas pressure (GS2, Air), 50 psi. The declustering potential (DP) was set at 
$-100 \mathrm{~V}$, whereas the collision energy (CE) was set at $-45 \mathrm{~V}$ with a collision energy spread (CES) of $15 \mathrm{~V}$. For comparison, the myricetin mixed with methanol $\mathrm{DPPH}^{\bullet}$ solution was also analyzed under the above UPLC-ESI-Q-TOF-MS conditions.

\section{3. $\mathrm{DPPH} \mathrm{H}^{\bullet}$ Radical-Trapping Analysis}

The $\mathrm{DPPH}^{\bullet}$ radical-trapping was determined as previously described [62]. Briefly, $80 \mu \mathrm{L}$ of $\mathrm{DPPH}^{\bullet}$ solution $(0.1 \mathrm{~mol} / \mathrm{L})$ was mixed with methanolic sample solutions at the indicated concentration $(x=0-10 \mu \mathrm{L}, 0.05 \mathrm{mg} / \mathrm{mL})$. The mixture was maintained at room temperature, and the absorbance was measured at $519 \mathrm{~nm}$ on a microplate reader. The percentage of $\mathrm{DPPH}^{\bullet}$ scavenging activity was calculated as follows (Equation (1)):

$$
\text { Inhibition } \%=\frac{A_{0}-A}{A_{0}} \times 100 \% \text {, }
$$

where $A_{0}$ is the absorbance of the control without the sample, and $A$ is the absorbance of the reaction mixture with the sample.

\subsection{PTIO`-Trapping Spectrophotometric Analysis}

The PTIO`-trapping analyses (at $\mathrm{pH} 4.5$ or $\mathrm{pH} 7.4$ ) were conducted based on our previously reported method [63]. In brief, the test sample solution $(x=4-20 \mu \mathrm{L}, 0.25 \mathrm{mg} / \mathrm{mL})$ was added to $(20-x)$ $\mu \mathrm{L}$ of $95 \%$ ethanol, followed by $80 \mu \mathrm{L}$ of an aqueous PTIO ${ }^{\bullet}$ solution. The aqueous PTIO ${ }^{\bullet}$ solution was prepared using a phosphate-buffer solution $(0.1 \mathrm{mM}, \mathrm{pH} 4.5$ or $\mathrm{pH} 7.4)$. The mixture was maintained at $30{ }^{\circ} \mathrm{C}$ for $1 \mathrm{~h}$, and the absorbance was subsequently measured at $560 \mathrm{~nm}$ using a microplate reader. The PTIO $\bullet$ percentage inhibition was calculated based on the formula presented in Section 3.3.

\subsection{Superoxide Anion $\left({ }^{\bullet} \mathrm{O}_{2}^{-}\right)$-Scavenging Spectrophotometric Analysis (Pyrogallol Autoxidation Method)}

The superoxide anion $\left({ }^{\bullet} \mathrm{O}_{2}{ }^{-}\right)$-trapping activity was determined using a method previously developed in our laboratory [64]. Briefly, a 5-25 $\mu \mathrm{L}$ sample solution $(0.5 \mathrm{mg} / \mathrm{mL})$ was added to a $0.05 \mathrm{M}$ Tris-HCl buffer ( $\mathrm{pH} 7.4$ ) containing $\mathrm{Na}_{2}$ EDTA (1 mM), and the total volume was adjusted to $980 \mu \mathrm{L}$ using a buffer. Pyrogallol $(20 \mu \mathrm{L})(1,2,3$-trihydroxylbenzene) solution (60 mM in $1 \mathrm{mM} \mathrm{HCl})$ was added to the sample, and the resulting mixture was vigorously agitated before being analyzed at $325 \mathrm{~nm}$ every $30 \mathrm{~s}$ for $5 \mathrm{~min}$. The ${ }^{\bullet} \mathrm{O}_{2}{ }^{-}$radical-trapping ability was calculated as follows (Equation (2)):

$$
\text { Inhibition } \%=\frac{\left(\frac{\Delta A_{325 \mathrm{~nm}, \text { control }}}{T}\right)-\left(\frac{\Delta A_{325 \mathrm{~nm}, \text { sample }}}{T}\right)}{\left(\frac{\Delta A_{325 \mathrm{~nm}, \text { control }}}{T}\right)} \times 100 \% \text {, }
$$

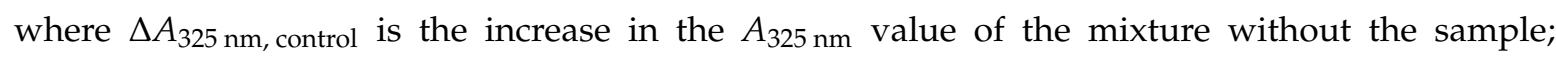

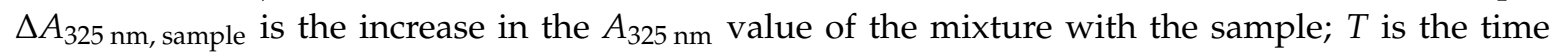
required for the determination ( $5 \mathrm{~min}$ in this case).

\subsection{Preferential Conformation Analysis by Computational Chemistry and Molecular Weight Calculation}

The preferential conformation was analyzed based on force fields by computational chemistry. In brief, the energy minimization of both M3OGa and myricetin were respectively calculated through molecular mechanics II (MM2) using the Chem3D Pro14.0 program (PerkinElmer, Waltham, MA, USA) [65-67]. The preferential conformation was expressed using the molecular models in Figure 6A-D.

The Q-TOF-MS analysis is characterized by highly accurate $m / z$ values, particularly molecular weights. The molecular weight calculation based on the formula is vital for comparison with the $m / z$ values from the Q-TOF-MS analysis. In the present study, the molecular weight calculations of M3OGa and myricetin were conducted based on the accurate relative atomic masses. The relative atomic masses of C, H, O, and N were 12.0000, 1.007825, 15.994915, and 14.003074, respectively [30]. 


\subsection{Statistical Analysis}

The results were reported as the mean $\pm \mathrm{SD}$ of three independent measurements, the $\mathrm{IC}_{50}$ values were calculated by linear regression analysis, and independent-sample $t$-tests were performed to compare the different groups. A $p$-value of less than 0.05 was considered statistically significant. The statistical analyses were performed using the SPSS software 17.0 (SPSS Inc., Chicago, IL, USA) for Windows. All of the linear regression analyses described in this paper were processed using version 6.0 of the Origin professional software.

\section{Conclusions and Perspective}

Myricetin-3-O-galactoside (M3OGa) and myricetin aglycone may trap free radicals via a chain reaction comprising of a propagation step and a termination step. The 3-O-galactosylation process can limit the redox-dependent antioxidant pathways at the propagation step; this makes myricetin-3-O-galactoside an inferior antioxidant compared to its aglycone. Nevertheless, both can afford similar RAF products at the termination step. This effect of 3-O-galactosylation confirmed that the antioxidative activities of phytophenols are differentiated at the propagation step rather than the termination step.

Supplementary Materials: The following are available: Supplementary File S1. Flavonol-3-O-galactoside and its aglycone; Supplementary File S2. The mass spectrum of the DPPH free radical; Supplementary File S3. Dose response curves in the antioxidant spectrophotometric analyses; Supplementary File S4. Certificate of analysis of myricetin-3-O-galactoside; Supplementary File S5. Certificate of analysis of myricetin.

Author Contributions: X.L. and D.C. conceived and designed the experiments; X.O. and M.L. performed the experiments and analyzed the data; X.L. wrote the paper. All authors read and approved the final manuscript.

Funding: This research was funded by the Guangdong Science and Technology Project (2017A050506043, 2017A030312009) and the National Nature Science Foundation of China (81573558).

Conflicts of Interest: The authors declare no conflict of interest.

\section{Abbreviations}

The following abbreviations are used in this manuscript:

$\begin{array}{ll}\text { DPPH } & \alpha, \alpha \text {-diphenyl- } \beta \text {-picrylhydrazyl radical } \\ \text { EDTA } & \text { ethylenediaminetetraacetic acid } \\ \text { ET } & \text { electron transfer } \\ \text { PTIO } & \text { r-phenyl-4,4,5,5-tetramethylimidazoline-1-oxyl 3-oxide radical } \\ \text { RAF } & \text { reactive oxygen species } \\ \text { ROS } & \text { standard deviation } \\ \text { SD } & \text { statistical product and service solutions } \\ \text { SPSS } & \text { tris-hydroxymethyl amino methane } \\ \text { Tris } & \text { ultra-performance liquid chromatography coupled with electrospray ionization } \\ \text { UPLC-ESI-Q- } & \text { quadrupole time-of-flight tandem mass spectrometry } \\ \text { TOF-MS } & \end{array}$

\section{References}

1. Karsten, C.M.; Pandey, M.K.; Figge, J.; Kilchenstein, R.; Taylor, P.R.; Rosas, M.; McDonald, J.U.; Orr, S.J;; Berger, M.; Petzold, D.; et al. Anti-inflammatory activity of IgG1 mediated by Fc galactosylation and association of FcgammaRIIB and dectin-1. Nat. Med. 2012, 18, 1401-1406. [CrossRef] [PubMed]

2. Noble, G.T.; Craven, F.L.; Voglmeir, J.; Sardzik, R.; Flitsch, S.L.; Webb, S.J. Accelerated enzymatic galactosylation of N-acetylglucosaminolipids in lipid microdomains. J. Am. Chem. Soc. 2012, 134, 13010-13017. [CrossRef] [PubMed]

3. Wang, Z.; Wang, S.; Xu, Z.; Li, M.; Chen, K.; Zhang, Y.; Hu, Z.; Zhang, M.; Zhang, Z.; Qiao, X.; et al. Highly Promiscuous Flavonoid 3-O-Glycosyltransferase from Scutellaria baicalensis. Org. Lett. 2019, 21, 2241-2245. [CrossRef] [PubMed] 
4. Feng, K.; Xu, Z.S.; Liu, J.X.; Li, J.W.; Wang, F.; Xiong, A.S. Isolation, purification, and characterization of AgUCGalT1, a galactosyltransferase involved in anthocyanin galactosylation in purple celery (Apium graveolens L.). Planta 2018, 247, 1363-1375. [CrossRef] [PubMed]

5. Guerin, M.E.; David, A.J.; Polo, M.A.S.; Marina, A. Structural Snapshots of the Reaction Center of Family GT6 $\alpha-1,3$-Galactosyltransferase with Native Substrates. Insights into the Catalytic Mechanism of Retaining Glycosyltransferases. Angew. Chem. Int. Ed. 2017. [CrossRef]

6. Lee, C.W.; Seo, J.Y.; Lee, J.; Choi, J.W.; Cho, S.; Bae, J.Y.; Sohng, J.K.; Kim, S.O.; Kim, J.; Park, Y.I. 3-O-Glucosylation of quercetin enhances inhibitory effects on the adipocyte differentiation and lipogenesis. Biomed. Pharmacoter. 2017, 95, 589-598. [CrossRef] [PubMed]

7. Timmermann, B.N.; Valcic, S.; Liu, Y.L.; Montenegro, G. Flavonols from Cryptocarya alba. Z. Naturforsch C 1995, 50, 898-899. [CrossRef]

8. Choi, S.J.; Tai, B.H.; Cuong, N.M.; Kim, Y.H.; Jang, H.D. Antioxidative and anti-inflammatory effect of quercetin and its glycosides isolated from mampat (Cratoxylum formosum). Food Sci. Biotechnol. 2012, 21, 587-595. [CrossRef]

9. Diaz, J.G.; Carmona, A.J.; Torres, F.; Quintana, J.; Estevez, F.; Herz, W. Cytotoxic activities of flavonoid glycoside acetates from Consolida oliveriana. Planta Med. 2008, 74, 171-174. [CrossRef]

10. Mattivi, F.; Guzzon, R.; Vrhovsek, U.; Stefanini, M.; Velasco, R. Metabolite profiling of grape: Flavonols and anthocyanins. J. Agric. Food Chem. 2006, 54, 7692-7702. [CrossRef]

11. Serreli, G.; Jerkovic, I.; Gil, K.A.; Marijanovic, Z.; Pacini, V.; Tuberoso, C.I.G. Phenolic Compounds, Volatiles and Antioxidant Capacity of White Myrtle Berry Liqueurs. Plant Food Hum. Nutr. 2017, 72, 205-210. [CrossRef] [PubMed]

12. Chen, S.; Fang, L.C.; Xi, H.F.; Guan, L.; Fang, J.B.; Liu, Y.L.; Wu, B.H.; Li, S.H. Simultaneous qualitative assessment and quantitative analysis of flavonoids in various tissues of lotus (Nelumbo nucifera) using high performance liquid chromatography coupled with triple quad mass spectrometry. Anal. Chim. Acta 2012, 724, 127-135. [CrossRef] [PubMed]

13. Ouyang, X.; Li, X.; Lu, W.; Zhao, X.; Chen, D. A Null B-Ring Improves the Antioxidant Levels of Flavonol: A Comparative Study between Galangin and 3,5,7-Trihydroxychromone. Molecules 2018, 23, 3083. [CrossRef] [PubMed]

14. Kim, D.O.; Lee, C.Y. Comprehensive Study on Vitamin C Equivalent Antioxidant Capacity (VCEAC) of Various Polyphenolics in Scavenging a Free Radical and its Structural Relationship. Crit. Rev. Food Sci. 2004, 44, 253-273. [CrossRef] [PubMed]

15. Musialik, M.; Kuzmicz, R.; Pawlowski, T.S.; Litwinienko, G. Acidity of hydroxyl groups: An overlooked influence on antiradical properties of flavonoids. J. Org. Chem. 2009, 74, 2699-2709. [CrossRef] [PubMed]

16. Djeradi, H.; Rahmouni, A.; Cheriti, A. Antioxidant activity of flavonoids: A QSAR modeling using Fukui indices descriptors. J. Mol. Model. 2014, 20, 2476. [CrossRef] [PubMed]

17. Amic, D.; Lucic, B. Reliability of bond dissociation enthalpy calculated by the PM6 method and experimental TEAC values in antiradical QSAR of flavonoids. Bioorgan. Med. Chem. 2010, 18, 28-35. [CrossRef] [PubMed]

18. Trouillas, P.; Marsal, P.; Siri, D.; Lazzaroni, R.; Duroux, J.-L. A DFT study of the reactivity of OH groups in quercetin and taxifolin antioxidants: The specificity of the 3-OH site. Food Chem. 2006, 97, 679-688. [CrossRef]

19. Lucarini, M.; Pedulli, G.F. Free radical intermediates in the inhibition of the autoxidation reaction. Chem. Soc. Rev. 2010, 39, 2106-2119. [CrossRef]

20. Huang, D.; Ou, B.; Prior, R.L. The chemistry behind antioxidant capacity assays. J. Agric. Food Chem. 2005, 53, 1841-1856. [CrossRef]

21. Losada-Barreiro, S.; Bravo-Diaz, C. Free radicals and polyphenols: The redox chemistry of neurodegenerative diseases. Eur. J. Med. Chem. 2017, 133, 379-402. [CrossRef] [PubMed]

22. Foti, M.C. Antioxidant properties of phenols. J. Pharm. Pharmacol. 2007, 59, 1673-1685. [CrossRef] [PubMed]

23. Lim, S.M.; Lee, H.S.; Jung, J.I.; Kim, S.M.; Kim, N.Y.; Seo, T.S.; Bae, J.S.; Kim, E.J. Cyanidin-3$\mathrm{O}$-galactoside-enriched Aronia melanocarpa extract attenuates weight gain and adipogenic pathways in high-fat diet-induced obese C57BL/6 mice. Nutrients 2019, 11, 1190. [CrossRef] [PubMed]

24. Inoue, H.; Maeda-Yamamoto, M.; Nesumi, A.; Murakami, A. Delphinidin-3-O-galactoside protects mouse hepatocytes from (-)-epigallocatechin-3-gallate-induced cytotoxicity via up-regulation of heme oxygenase-1 and heat shock protein 70. Nutr. Res. 2012, 32, 357-364. [CrossRef] [PubMed] 
25. Reina, M.; Martinez, A. A new free radical scavenging cascade involving melatonin and three of its metabolites (3OHM, AFMK and AMK). Comput. Theor. Chem. 2018, 1123, 111-118. [CrossRef]

26. Bayat, A.; Fattahi, A. A quantum chemical study on the $\mathrm{OH}$ radical quenching by natural antioxidant fisetin. J. Phys. Org. Chem. 2017, 30, 8. [CrossRef]

27. Liang, M.S.; Li, X.C.; Ouyang, X.J.; Xie, H.; Chen, D.F. Antioxidant Mechanisms of Echinatin and Licochalcone, A. Molecules 2019, 24, 14. [CrossRef]

28. Hassan, I.; Pinto, S.; Weisbecker, C.; Attygalle, A.B. Competitive Deprotonation and Superoxide O-2(-center dot) Radical-Anion Adduct Formation Reactions of Carboxamides under Negative-Ion Atmospheric-Pressure Helium-Plasma Ionization (HePI) Conditions. J. Am. Soc. Mass Spectr. 2016, 27, 394-401. [CrossRef] [PubMed]

29. Liu, Y.R.; Li, W.G.; Chen, L.F.; Xiao, B.K.; Yang, J.Y.; Yang, L.; Zhang, C.G.; Huang, R.Q.; Dong, J.X. ABTS ${ }^{+\bullet}$ scavenging potency of selected flavonols from Hypericum perforatum L. by HPLC-ESI/MS QQQ: Reaction observation, adduct characterization and scavenging activity determination. Food Res. Int. 2014, 58, 47-58. [CrossRef]

30. Gross, J.H. Mass Spectrometry, 2nd ed.; Science Press: Beijing, China, 2013; pp. 718-719.

31. Li, X. Antioxidant Change in Biosynthesis from Naringenin Chalcone to Flavonoid Apingenin. ChemistrySelect 2019, 4, 5155-5159.

32. Liu, Q.; Li, X.; Ouyang, X.; Chen, D. Dual Effect of Glucuronidation of a Pyrogallol-Type Phytophenol Antioxidant: A Comparison between Scutellarein and Scutellarin. Molecules 2018, 23, 3225. [CrossRef] [PubMed]

33. Li, X.; Chen, B.; Xie, H.; He, Y.; Zhong, D.; Chen, D. Antioxidant Structure-Activity Relationship Analysis of Five Dihydrochalcones. Molecules 2018, 23, 1162. [CrossRef] [PubMed]

34. Li, X.; Xie, H.; Zhan, R.; Chen, D. Effect of Double Bond Position on 2-Phenyl-benzofuran Antioxidants: A Comparative Study of Moracin C and Iso-Moracin C. Molecules 2018, 23, 754. [CrossRef] [PubMed]

35. Li, X.; Ouyang, X.; Cai, R.; Chen, D. 3',8"-Dimerization Enhances the Antioxidant Capacity of Flavonoids: Evidence from Acacetin and Isoginkgetin. Molecules 2019, 24, 2039. [CrossRef] [PubMed]

36. Wang, G.; Li, X.C.; Zeng, H.P. Synthesis, antioxidation activity of (E)-9-p-Tolyl-3-2-(8-hydroxy-quinol2-yl)vinyl]-carbazole and (E)-9-(p-Anisyl)-3-2-(8-hydroxy-quinol-2-yl)vinyl]-carbazole and their induction proliferation of mesenchymal stem cells. Acta Chim. Sin. 2009, 67, 974-982.

37. Ingold, K.U.; Pratt, D.A. Advances in radical-trapping antioxidant chemistry in the 21st century: A kinetics and mechanisms perspective. Chem. Rev. 2014, 114, 9022-9046. [CrossRef] [PubMed]

38. Xie, J.; Schaich, K.M. Re-evaluation of the 2,2-Diphenyl-1-picrylhydrazyl Free Radical (DPPH•) Assay for Antioxidant Activity. J. Agric. Food Chem. 2014, 62, 4251-4260. [CrossRef]

39. Markovic, S.; Tosovic, J. Comparative study of the antioxidative activities of caffeoylquinic and caffeic acids. Food Chem. 2016, 210, 585-592. [CrossRef]

40. Liu, Z.Q. Chemical methods to evaluate antioxidant ability. Chem. Rev. 2010, 110, 5675-5691. [CrossRef]

41. Litwinienko, G.; Ingold, K.U. Solvent effects on the rates and mechanisms of reaction of phenols with free radicals. Acc. Chem. Res. 2007, 40, 222-230. [CrossRef]

42. Iuga, C.; Alvarez-Idaboy, J.R.; Russo, N. Antioxidant activity of trans-resveratrol toward hydroxyl and hydroperoxyl radicals: A quantum chemical and computational kinetics study. J. Org. Chem. 2012, 77, 3868-3877. [CrossRef] [PubMed]

43. Foti, M.C.; Daquino, C.; Mackie, I.D.; DiLabio, G.A.; Ingold, K.U. Reaction of phenols with the 2,2-diphenyl-1-picrylhydrazyl radical. Kinetics and DFT calculations applied to determine ArO-H bond dissociation enthalpies and reaction mechanism. J. Org. Chem. 2008, 73, 9270-9282. [CrossRef] [PubMed]

44. Schrauben, J.N.; Cattaneo, M.; Day, T.C.; Tenderholt, A.L.; Mayer, J.M. Multiple-site concerted proton-electron transfer reactions of hydrogen-bonded phenols are nonadiabatic and well described by semiclassical Marcus theory. J. Am. Chem. Soc. 2012, 134, 16635-16645. [CrossRef] [PubMed]

45. Goldstein, S.; Russo, A.; Samuni, A. Reactions of PTIO and carboxy-PTIO with ${ }^{\bullet} \mathrm{NO},{ }^{\bullet} \mathrm{NO} 2$, and $^{\bullet} \mathrm{O}_{2}{ }^{-}$. J. Biol. Chem. 2003, 278, 50949-50955. [CrossRef] [PubMed]

46. Das, A.B.; Nauser, T.; Koppenol, W.H.; Kettle, A.J.; Winterbourn, C.C.; Nagy, P. Rapid reaction of superoxide with insulin-tyrosyl radicals to generate a hydroperoxide with subsequent glutathione addition. Free Radic. Biol. Med. 2014, 70, 86-95. [CrossRef] [PubMed]

47. Jovanovic, S.V.; Hara, Y.; Steenken, S.; Simic, M.G. Antioxidant Potential of Gallocatechins. A Pulse Radiolysis and Laser Photolysis Study. J. Am. Chem. Soc. 1995, 117, 9881-9888. [CrossRef] 
48. Quintero-Saumeth, J.; Rincon, D.A.; Doerr, M.; Daza, M.C. Concerted double proton-transfer electron-transfer between catechol and superoxide radical anion. Phys. Chem. Chem. Phys. 2017, 19, 26179-26190. [CrossRef] [PubMed]

49. Nakayama, T.; Uno, B. Importance of Proton-Coupled Electron Transfer from Natural Phenolic Compounds in Superoxide Scavenging. Chem. Pharm. Bull. 2015, 63, 967-973. [CrossRef]

50. Holtomo, O.; Nsangou, M.; Fifen, J.J.; Motapon, O. DFT study of the effect of solvent on the H-atom transfer involved in the scavenging of the free radicals ${ }^{\bullet} \mathrm{HO}_{2}$ and ${ }^{\bullet} \mathrm{O}_{2}{ }^{-}$by caffeic acid phenethyl ester and some of its derivatives. J. Mol. Model. 2014, 20, 13. [CrossRef]

51. Li, X.; Xie, Y.; Xie, H.; Yang, J.; Chen, D. $\pi-\pi$ Conjugation Enhances Oligostilbene's Antioxidant Capacity: Evidence from $\alpha$-Viniferin and Caraphenol A. Molecules 2018, 23, 694. [CrossRef]

52. Lin, J.; Li, X.; Chen, B.; Wei, G.; Chen, D. E-Configuration Improves Antioxidant and Cytoprotective Capacities of Resveratrols. Molecules 2018, 23, 1790. [CrossRef] [PubMed]

53. Li, X.C. Comparative Study of 1,1-Diphenyl-2-picryl-hydrazyl Radical (DPPH ${ }^{\bullet}$ ) Scavenging Capacity of the Antioxidant Xanthones Family. Chemistryselect 2018, 3, 13081-13086. [CrossRef]

54. Li, X.; Chen, B.; Zhao, X.; Chen, D. 2-Phenyl-4,4,5,5-tetramethylimidazoline-1-oxyl 3-oxide Radical (PTIO•) Trapping Activity and Mechanisms of 16 Phenolic Xanthones. Molecules 2018, 23, 1692. [CrossRef] [PubMed]

55. Li, X.; Tian, Y.; Wang, T.; Lin, Q.; Feng, X.; Jiang, Q.; Liu, Y.; Chen, D. Role of the $p$-Coumaroyl Moiety in the Antioxidant and Cytoprotective Effects of Flavonoid Glycosides: Comparison of Astragalin and Tiliroside. Molecules 2017, 22, 1165. [CrossRef] [PubMed]

56. Li, X.C.; Jiang, Q.; Chen, B.; Luo, X.L.; Chen, D.F. Structure-Activity Relationship and Prediction of the Electron-Transfer Potential of the Xanthones Series. Chem. Open 2018, 7, 730-736. [CrossRef] [PubMed]

57. MacAleese, L.; Hermelin, S.; Hage, K.E.; Chouzenoux, P.; Kulesza, A.; Antoine, R.; Bonacina, L.; Meuwly, M.; Wolf, J.P.; Dugourd, P. Sequential Proton Coupled Electron Transfer (PCET): Dynamics Observed over 8 Orders of Magnitude in Time. J. Am. Chem. Soc. 2016, 138, 4401-4407. [CrossRef] [PubMed]

58. Rajan, V.K.; Muraleedharan, K. A computational investigation on the structure, global parameters and antioxidant capacity of a polyphenol, Gallic acid. Food Chem. 2017, 220, 93-99. [CrossRef] [PubMed]

59. Martinez, A.; Hernandez-Marin, E.; Galano, A. Xanthones as antioxidants: A theoretical study on the thermodynamics and kinetics of the single electron transfer mechanism. Food Funct. 2012, 3, 442-450. [CrossRef]

60. Li, X.C.; Han, L.; Li, Y.R.; Zhang, J.; Chen, J.M.; Lu, W.B.; Zhao, X.J.; Lai, Y.Y.; Chen, D.F.; Wei, G. Protective Effect of Sinapine against Hydroxyl Radical-Induced Damage to Mesenchymal Stem Cells and Possible Mechanisms. Chem. Pharm. Bull. 2016, 64, 319-325. [CrossRef]

61. Xie, Y.; Li, X.; Chen, J.; Deng, Y.; Lu, W.; Chen, D. pH Effect and Chemical Mechanisms of Antioxidant Higenamine. Molecules 2018, 23, 2176. [CrossRef]

62. Li, X.C.; Mai, W.Q.; Chen, D.F. Chemical study on protective effect against hydroxyl-induced DNA damage and antioxidant mechanism of myricitrin. J. Chin. Chem. Soc. 2014, 61, 383-391. [CrossRef]

63. Li, X.C. 2-Phenyl-4,4,5,5-tetramethylimidazoline-1-oxyl 3-Oxide (PTIO•) Radical Scavenging: A New and Simple Antioxidant Assay In Vitro. J. Agric. Food Chem. 2017, 65, 6288-6297. [CrossRef] [PubMed]

64. Li, X.C. Improved pyrogallol autoxidation method: A reliable and cheap superoxide-scavenging assay suitable for all antioxidants. J. Agric. Food Chem. 2012, 60, 6418-6424. [CrossRef] [PubMed]

65. Liu, Z.; Barigye, S.J.; Shahamat, M.; Labute, P.; Moitessier, N. Atom Types Independent Molecular Mechanics Method for Predicting the Conformational Energy of Small Molecules. J. Chem. Inf. Model. 2018, 58, $194-205$. [CrossRef] [PubMed]

66. Ciric-Marjanovic, G.; Trchova, M.; Konyushenko, E.N.; Holler, P.; Stejskal, J. Chemical oxidative polymerization of aminodiphenylamines. J. Phys. Chem. B 2008, 112, 6976-6987. [CrossRef] [PubMed]

67. Kaminsky, J.; Jensen, F. Conformational Interconversions of Amino Acid Derivatives. J. Chem. Theory Comput. 2016, 12, 694-705. [CrossRef]

Sample Availability: Sample of the compound myricetin-3-O-galactoside is available from the authors. 